\title{
Políticas públicas em educação: uma proposta participativa de formação de professores
}

\author{
Government policies in education: a participative \\ proposal for teachers" improvement
}

\author{
Elisabete Ferreira Esteves CAMPOS
}

\begin{abstract}
RESUMO
Os resultados dos exames nacionais e internacionais veiculados pela mídia, apresentando desempenho insatisfatório dos alunos, especialmente das escolas públicas, colocam o tema "educação" em destaque. A escola tem sido alvo de duras críticas pela baixa qualidade do ensino. Ocorre que nem sempre a análise do problema leva em conta o contexto político, econômico, cultural e social de nosso país. As medidas necessárias são amplas e exigem investimentos também no campo social e econômico. No entanto, temos nos deparado com o discurso da falta de competência dos educadores como causa principal das dificuldades de aprendizagem dos alunos. Sabemos que a desvalorização da profissão docente, a formação precária e baixos salários têm consequiências graves, inclusive levando o profissional a assumir uma carga horária de trabalho além da considerada aceitável. Mas as políticas públicas têm se voltado muito mais para os métodos, diretrizes, materiais didáticos, deixando em segundo plano os responsáveis pelas ações pedagógicas em aulas: os professores. Estes são vistos como aqueles que devem colocar em prática os currículos e programas definidos nas instâncias superiores. Neste texto, procuro destacar a necessária participação dos docentes na discussão sobre políticas educacionais, inclusive para que possamos construir um outro perfil profissional. Acredito que a formação de professores - inicial ou contínua - deva ocorrer numa perspectiva de formação para a participação e construção de autonomia intelectual. É preciso que a formação de professores considere as discussões sobre os problemas sociais, econômicos, educacionais, contribuindo na elaboração de políticas públicas com vistas à melhoria da qualidade da educação.
\end{abstract} públicas.

Palavras-chave: formação de professores, participação, políticas 


\begin{abstract}
The result of national and international tests divulgated by the media, showing unsatisfactory performance among students, particularly those from public schools, to draw the attention to the topic of education. The school has been subject to hard criticism due to its low quality. The analysis of the problem does not always take into account the political, economic, social and cultural background of our country. The necessary measures are broad and also demand investments in the social and economic areas. However, the educators" lack of competence belief has been presented as a major cause of the students" difficulty in learning. The disregard for teaching profession, the poor educational background and the low salaries have serious consequences, even forcing the professional to work beyond a reasonable amount of time. Nevertheless, governmental education policies have been focused on methods, goals, textbooks and alike, putting aside the responsible for the pedagogical work: the teachers. They are seen as the ones that have to put into practice the curricula and programs defined by higher levels of power. The present dissertation aims to make salient the necessary participation of the teachers in the discussion about the educational policies so that another professional profile can be built. It also highlights that the first formation and continuous professional improvement of the teachers should lead to participation and construction of intellectual autonomy, taking into account the discussions about the social, economic and education problems in order to contribute to the elaboration of governmental policies to enhance the quality of education.
\end{abstract}

Index Terms: governmental policies, participation, teachers professional improvement. 
Que educador seria eu se não me sentisse movido por forte impulso que me faz buscar, sem mentir, argumentos convincentes na defesa dos sonhos por que luto? Na defesa da razão de ser da esperança com que atuo como educador.

(Paulo Freire)

\section{Introdução}

A sociedade atual tem progressivamente se envolvido com preocupações acerca da educação escolar oferecida às crianças e aos adolescentes. De uma forma mais ampla, o tema "educação" ganha espaço na mídia, nas empresas, nas organizações não-governamentais (ONGs), em projetos sociais e na política, com uma multiplicidade de interesses e enfoques. Desta forma, as bases filosóficas que apóiam as propostas e projetos educativos das diversas instituições se diferenciam de acordo com a forma pela qual cada uma concebe a educação.

Enquanto prática histórica, a educação formal tem o desafio de responder às demandas que os contextos políticos e sociais the colocam. Nos últimos tempos, a escola vem enfrentando críticas acerbadas da sociedade que questiona a qualidade da educação e mais diretamente a competência dos docentes. Pesquisas denunciam que muitos alunos freqüentam a escola, há 4 ou 5 anos, sem sequer saberem ler e escrever, e que tantos outros, em situações correlatas, são considerados "analfabetos funcionais". É denunciada, em função das constantes investigações, a ineficiência da escola em formar alunos que possam "adquirir" e manifestar os conhecimentos necessários para atuarem socialmente.

$\mathrm{O}$ fato é que o sistema educacional brasileiro passa por mais um momento crítico, e analisar algumas pistas sobre as possíveis razões, é um desafio para todos os que se preocupam com esta questão. Estamos vivendo um processo de mudanças constantes no qual os conceitos, os valores e as "certezas" que durante muitos anos foram tidas como "verdades absolutas", sob um determinado paradigma vigente, dão lugar a um outro que ressalta 
— com a propriedade deste novo século — a relatividade e o caráter inacabado do conhecimento.

Já se torna cada vez mais difícil introduzir e sustentar conceitos sob uma visão de mundo relacionada à noção de espaço e tempo absolutos, e à objetividade pseudo-científica. Como se sabe, todo conhecimento produzido nas mais diversas áreas de atuação humana assume um caráter de provisoriedade. A velocidade das descobertas, dos avanços científicos, tecnológicos, e dos consequientes impactos sociais e ambientais podem trazer benefícios, - embora não seja para todos — mas também colocar em risco a vida no planeta.

O impacto das inovações provoca nas escolas a necessidade de mudanças, as quais, por diversas razões, nem sempre se efetivam - ou podem ser efetivadas - gerando situações conflituosas no interior das próprias escolas e a inquietude dos docentes frente às dificuldades de diversas ordens. Os meios de comunicação - cada vez mais rápidos e sofisticados em nossa sociedade globalizada - continuadamente transmitem valores e atitudes que são assumidas por muitas pessoas sem qualquer análise crítica de seu sentido e significado (SILVA, 2002). A violência, as injustiças e outros problemas sociais estão presentes na vida cotidiana - nos lares e nas mentes - e se transformam subitamente em temas escolares, sem a pertinente orientação pedagógica, valorativa e ética.

Diante desse panorama, é preciso expressar a expectativa de que as escolas se reorganizem com base em uma nova/outra concepção de conhecimento que progressivamente as levem a abandonar práticas pedagógicas tradicionalmente centradas na reprodução ou no simples acumular de informações sem o devido posicionamento crítico e ético. Mas ocorre que nem sempre os docentes têm claro porque, como e para que ensinar um conteúdo e não outro, como lidar com as relações que estão envolvidas no processo educativo e ainda qual o papel da escola na atualidade. 


\title{
1 Reflexões sobre o panorama atual
}

Apesar dessa falta de clareza, os docentes precisam lidar com a demanda que hoje se coloca em termos de discurso, qual seja a formação de cidadãos pensantes, criativos, que possam posicionar-se de maneira crítica diante da realidade e conquistar autonomia de ser, de estar e de saber. São esses os objetivos centrais citados nos Parâmetros Curriculares Nacionais do Ministério da Educação e Cultura (PCNs do MEC), supostamente assumidos por um grande número de escolas públicas.

Mas, essa expectativa que se coloca em relação às escolas exige algumas reflexões. Como alerta Arroyo:

\begin{abstract}
As escolas são mais destacadas nas políticas, na teoria, do que os seus profissionais. Estes aparecem como um apêndice, um recurso preparado ou despreparado, valorizado ou desvalorizado. Depois que se decide a construção da escola, os currículos e seus parâmetros, as políticas de qualidade ou de democratização da educação... pensam nos recursos humanos que darão conta da tarefa. (ARROYO, 2000, p. 9-10)
\end{abstract}

De fato, as políticas públicas têm se voltado muito mais para o estabelecimento de diretrizes de ensino, elaboração de materiais didáticos e métodos, deixando de lado os que efetivamente educam nas instituições escolares: os docentes. São eles que nas escolas educam os cidadãos pensantes, autônomos, criativos e participativos. Mas, como os docentes compreendem o sentido e os significados de tal proposta que pode parecer apenas mais um "jargão"?

Ao se colocar para a escola a responsabilidade de formar cidadãos, é preciso saber em que medida - na formação dos docentes - são oferecidas as condições necessárias para discutir, para compreender o significado de "cidadania" na atual sociedade capitalista globalizada; discutir para compreender o sentido de Educação na atualidade e os vieses ideológicos das propostas teóricas com as quais as escolas se deparam, como nos alerta Severino (2001). 
A ausência de discussões como essas fazem com que os docentes, na dança das teorias, transitem de uma concepção à outra, sem posicionarem-se claramente e sem parecerem assumir os compromissos que novas/outras posições pedagógicas suscitam.

Talvez porque ainda predomine uma concepção de formação docente livresca e transmissiva, considerando os professores apenas como reprodutores de projetos educativos idealizados por outros; reprodutores de "modismos" ou de teorias pedagógicas, em detrimento de discussões coletivas que os levem a refletir — tomando posição e construindo uma visão pedagógica atual e diferenciada - sobre os problemas educacionais no contexto do presente, sobre o papel da escola, sobre as concepções de educação recorrentes e sobre sua própria prática educativa no desempenho de sua profissão.

Tratar os docentes como "executores de teorias", "implementadores de currículos", de "programas" ou "aplicadores de material didático", significa cultivar relações de poder entre os que definem as políticas de educação e os docentes que devem ser mantidos no patamar inferior ao desses "profissionais pensantes", como reprodutores ou meros executores de suas idéias pedagógicas. Essa prática não possibilita aos docentes desvendar as ideologias que permeiam as diferentes propostas pedagógicas e tão pouco compreender para que se educa, e o seu papel nesse processo.

Apesar dos discursos progressistas defenderem, há décadas, uma postura educacional tendo em vista a emancipação do sujeito, é notório o fortalecimento de um corpo teórico que mantém a prática educativa numa perspectiva simplesmente reproducionista e obsoleta. Isto se dá - dentre outros fatores - porque as teorias e políticas públicas nem sempre são ou podem ser - analisadas criticamente pelos docentes de forma a provocar reflexões e debates para problematizar a prática educativa. Tais políticas desconsideram que a relação educativa é uma relação de pessoas, e o conhecimento se constrói nessa relação. 
Para muitos, os referenciais teóricos devem simplesmente ser colocados em prática - como se isso fosse possível - entendendo que o professor não pode ser compositor e já é muito considerá-lo simplesmente intérprete. Sendo assim, para esses intelectuais, muitos deles implementadores de políticas públicas, o professor precisa assumir as "práticas que deram certo", práticas que, através de pesquisas de outros inclusive em outros países - se mostraram comprovadamente eficientes.

Há alguns anos, a educação na Finlândia ganhou destaque na mídia por ter sido campeã no Programme for International Student Assesment $(\mathrm{PISA})^{1}$ e houve uma retomada da discussão sobre o método fônico na alfabetização, como se o resultado das aprendizagens dependesse apenas do método de ensino. Muitos defendem o uso do método fônico por ter sido bem sucedido em países como Finlândia, França e Estados Unidos.

Diante de idéias como essas, não podemos deixar de formular incisivamente algumas questões: As práticas bem sucedidas e consideradas desejáveis são práticas eficientes para quem? Em que contextos políticosociais foram bem sucedidas e por quais razões? Que objetivos pedagógicos ou da Educação essas práticas visaram nos contextos de sucesso de sua realização? Será que tais práticas podem ser simplesmente reproduzidas em qualquer contexto?

Entendo, como Freire (2001, p. 97), que “[...] a visão ou a compreensão dos direitos humanos e da educação depende de como eu me vejo no mundo politicamente, depende de com quem eu estou, a serviço de quem e a serviço de que eu sou um educador". Estas são questões relevantes a serem debatidas com os docentes, porque constituem a base da proposta educativa que será assumida e defendida; e implicam assumir atitudes de investigação, reflexão, reinvenção e não simples reprodução.

\footnotetext{
${ }^{1}$ Foi lançado em 2000, com avaliação dos alunos de 32 países por meio de prova de competência ao final da Educação Básica. O melhor resultado em leitura foi da Finlândia e o pior foi do Brasil. O programa avalia, a cada três anos, competências em leitura, matemática e ciências, alternadamente (www.pisa.oecd.org).
} 
Não estou sugerindo que os resultados das avaliações não tenham validade, mas não podemos utilizá-los sem uma análise contextualizada, apenas estabelecendo ranking entre os países, ou mesmo entre as escolas.

Não podemos aceitar que resultados de avaliações justifiquem a implantação de políticas públicas, desconsiderando o contexto político, social, econômico e cultural dos países que participam das avaliações. Da mesma forma, as avaliações nacionais não podem desconsiderar esse contexto.

No caso da alfabetização, por exemplo, a questão não é substituir o “construtivismo" pelo "método fônico", como muitos argumentam. Ainda que se reconheça a consciência fonologia como um aspecto importante, não se pode reduzir a alfabetização a treino, desconsiderando o pensamento da criança. Por outro lado, adotar os pressupostos da psicogênese da língua escrita não significa que há uma forma única de alfabetizar.

O problema, neste caso, é muito maior, uma vez que a metodologia precisa estar vinculada à discussão sobre democratização do ensino e conseqüentemente formação de professores. Sabemos que a psicogênese da língua escrita gerou diferentes interpretações e em muitos casos o entendimento equivocado implicou em deixar os alunos "descobrirem sozinhos", como se a didática fosse irrelevante.

A ausência de fóruns de discussões envolvendo os docentes para debater sobre as pesquisas, as diferentes abordagens teóricas, a gestão de aulas e tantos outros temas relevantes, significa desconsiderá-los como sujeitos do processo vivo de ensinar e aprender, agravando os problemas de ensino e aprendizagem — não só de alfabetização.

Em nosso país as políticas públicas ainda se justificam como se “[...] ser professor(a) fosse um cata-vento que gira à mercê da última vontade política e da última demanda tecnológica." (ARROYO, 2000, p. 24). Sair desse lugar é nosso desafio, para construir um outro olhar, uma outra imagem, de um profissional que tem que lidar com questões metodológicas, 
com as teorias e obras pedagógicas não como um fim em si mesmas, mas sobretudo, como mediação da relação dialógica que se estabelece com os alunos.

Assim como os alunos, os professores também aprendem a partir de e levando em conta os conhecimentos construídos ao longo de sua história de vida profissional e pessoal.

Tais idéias parecem justificar a importância de uma política de formação docente que considere o envolvimento dos professores em debates nas mais diversas instâncias, favorecendo uma postura participativa e a construção de autonomia intelectual.

Não podemos mais aceitar que os resultados de exames nacionais ou internacionais sejam utilizados quer para responsabilizar os docentes, quer para implantar novos métodos, novos referenciais teóricos ou materiais didáticos, desconsiderando o sujeito-professor no processo educativo.

Seria valioso para a educação se em cada Unidade Escolar a comunidade educativa - da qual os professores fazem parte - tivesse a possibilidade de interagir, de identificar e discutir os problemas escolares para compreender suas origens bem como os limites e possibilidades de ação para solucioná-los — inclusive encaminhando propostas e reivindicações às instâncias competentes — o que não significa assumir uma postura ingênua de acreditar que tudo deve ser modificado nem uma postura conformista de acreditar que nada pode ser feito. A

[...] comunidade educativa é uma construção teórica e normativa, um ideal de democratização e de participação emancipatória ou, pelo contrário, uma construção manipulante na base de uma participação meramente funcional, consoante àquelas distintas políticas. (LIMA, 2001, p. 135)

Geralmente, nas escolas, é a segunda situação que tem prevalecido. A ausência de uma cultura participativa é histórica em nosso país, e vem se perpetuando nas práticas escolares. 
Por outro lado, discutem-se, nos mais diversos fóruns, novos significados para a Educação, que se expressem mais justos e socialmente satisfatórios para o tempo presente. Transformar essa idéia em prática educativa é, contudo, uma tarefa extremamente complexa porque passa por interesses ideológicos e pelas relações de poder que obstaculizam que se assuma um novo pensar imbricado a um novo agir.

É possível, pois, manter a expectativa de uma escola que forme sujeitos letrados, autônomos, criativos e participativos, se os professores não vivenciam justamente a experiência considerada desejável de autonomia, de participação, de livre pensar e de criatividade?

\section{Formação para a autonomia}

As idéias progressistas ${ }^{2}$ que reivindicam a conquista de autonomia, entendida como maior participação política e social, para agir sobre a realidade buscando relações menos assimétricas, pode ganhar outros significados num contexto neoliberal. No âmbito educacional, a autonomia pode significar apenas transferência da responsabilidade pela qualidade do ensino para escolas e docentes, sem que estejam acompanhadas das condições necessárias para alcançar a qualidade desejada. Em nome da autonomia, a equipe escolar passa a ser vista como única responsável pelos índices de alfabetização e aprendizagem dos alunos, numa visão simplista e reducionista.

\footnotetext{
${ }^{2} \mathrm{O}$ termo "progressista" foi amplamente utilizado por Paulo Freire. Para o autor, não é fácil perfilar o educador progressista ou o reacionário sem correr o risco de cair em simplismos. "Situando-me entre os educadores e as educadoras progressistas do Brasil, hoje, diria que nos assumir assim significa, por exemplo, trabalhar lucidamente em favor da escola pública, em favor da melhoria de seus padrões de ensino, em defesa da dignidade dos docentes, de sua formação permanente. Significa lutar pela educação popular, pela participação crescente das classes populares nos conselhos de comunidade, de bairro, de escola. Significa incentivar a mobilização e a organização não apenas de sua própria categoria mas dos trabalhadores em geral como condição fundamental da luta democrática com vistas à transformação necessária e urgente da sociedade brasileira. FREIRE, Paulo (1995). A Educação na Cidade. 2. ed. Cortez Editora: São Paulo. p. 50.
} 
Para abordar essa questão realizei pesquisa com Professoras de escolas públicas, assumindo como hipótese que o contexto escolar, as políticas públicas, as oportunidades de formação em serviço e as interações pedagógicas do dia-a-dia influenciam o trabalho dos professores, condicionando-os a uma ação mais ou menos autônoma.

Do ponto de vista conceitual por mim assumido, autonomia não significa liberdade para trabalhar sozinho ou fazer o que quiser, ao contrário, é uma construção que se efetiva na relação com o outro e com o conhecimento, nas possibilidades de participação em diferentes instâncias e nas tomadas de decisões.

$\mathrm{Na}$ referida pesquisa, as Professoras citaram diferentes aspectos que, segundo elas, contribuem ou limitam as possibilidades de construção da autonomia nos termos aqui definidos. Dentre as limitações, citaram a exclusão dos docentes na definição de políticas públicas, a não participação na organização escolar, nos colegiados, nos processos decisórios e na elaboração do Projeto Político Pedagógico - o que compromete um ensino que possa ser considerado de melhor qualidade.

O trabalho com a diversidade também foi citado como dificultador porque, ao terem que assumir a responsabilidade de ensinar alunos com diferentes histórias de vida, diferentes culturas, conhecimentos, e principalmente alunos com algum tipo de deficiência, sentem-se desamparadas e sem condições de responsabilizar-se sozinhas pelo sucesso na aprendizagem e alfabetização de todos. A proposta de uma "educação inclusiva" tão presente nos discursos e nas políticas públicas tem se revelado como uma demanda muito mais dos docentes. Não tem havido como contrapartida as condições estruturais necessárias e o investimento no sujeito-professor, que se depara com inúmeros e graves problemas para os quais precisa encontrar soluções, muitas vezes sozinho. 
Apesar do discurso da diversidade, os exames de avaliação padronizados não respeitam as especificidades e necessidades educacionais dos alunos e desconsideram que a educação ocorre num contexto.

As dificuldades estruturais enfrentadas pelos docentes, como por exemplo, espaços escolares inadequados, elevado número de alunos por sala, falta de tempo na carga horária para estudar, participar de cursos, planejar, discutir em reuniões coletivas com vistas à superação dos problemas do cotidiano, segundo as Professoras que participaram da pesquisa, comprometem a construção da autonomia docente e a qualidade do ensino. Além disso, sentem-se mergulhadas nos afazeres diários durante todo o tempo em que permanecem na escola, sem o necessário distanciamento para análise e reflexão sobre a prática, de forma compartilhada com toda a equipe escolar.

As políticas públicas nem sempre vão ao encontro das necessidades da profissão ou do enfrentamento dos problemas escolares. A progressão continuada, por exemplo, foi implantada sem a necessária discussão acerca da ideologia que permeia tal proposta e não foram oferecidas as condições reais para sua efetivação. O resultado é que hoje, em muitas escolas, ainda se realiza um trabalho seriado e promovem-se alunos sem a reorganização do sistema de avaliação. É o fracasso de uma política implantada que exclui os docentes de um processo de discussão e de formação.

As formas burocráticas da organização escolar, as relações hierárquicas decorrentes de cargos e conhecimentos, a escassez de discussões coletivas no âmbito escolar, foram aspectos citados, pelas Professoras que participaram da pesquisa, como entraves para a construção de uma ação pedagógica considerada de melhor qualidade. A falta de participação na elaboração do Projeto Político Pedagógico — na maioria das vezes por não haver tempo suficiente - demonstra que o mesmo pode ser considerado apenas como documento burocrático e não como o instrumento que sistematiza uma proposta de educação, com base em princípios 
assumidos coletivamente. A participação em colegiados ainda é muito incipiente, gerando entraves para uma cultura participativa e democrática. A descentralização é um tema polêmico e problemático. Martins (2002) considera que:

\begin{abstract}
A despeito de todas as tentativas encetadas por diferentes experiências governamentais com o intuito de implementar processos descentralizadores em seus sistemas de ensino, invariavelmente vistos como a possibilidade de outorgar autonomia à própria rede de escolas, os limites postos por mecanismos burocráticos e por uma insistente tradição centralizadora - aliada à tradição patrimonialista - parecem construir um campo de tensão no planejamento da área. Destaque-se a reprodução, no cotidiano, das representações do universo político: de um lado, um Estado excessivamente normatizador, e de outro, atores razoavelmente vulneráveis às trocas político-administrativas e às mudanças permanentes nos planos, programas e projetos que se sucedem ou se sobrepõem (MARTINS, 2002, p. 135).
\end{abstract}

Frente a essas questões e às limitações apontadas pelas Professoras, é possível então concluir que o discurso de autonomia tão presente na mídia, nos documentos, nas propostas oficiais, pode significar mera transferência de enormes responsabilidades sociais para as escolas e professores, sem que estejam acompanhadas das condições de realização imprescindíveis. Essa idéia ficou bastante contundente nas manifestações das Professoras na pesquisa que realizei. São questões relevantes que precisam ser consideradas quando se analisa os resultados de qualquer avaliação institucional, encaminhando uma discussão crítica da problemática educacional e da formação de professores.

Por sua vez, no âmbito escolar, o Projeto Político Pedagógico representa uma das formas de luta para superar o determinismo estrutural e, certamente, ganhará concretude - no sentido marxista de ser compreendido e levado em conta em termos multiplamente determinados - ao ser assumido coletivamente pela equipe escolar na qual os professores têm papel fundamental como atores desse processo. 
Ao conceituar o papel docente nestes termos, entendo como um grande desafio a abertura de espaços de debate com a participação dos docentes na definição de políticas públicas que passem a investir, prioritariamente, no sujeito-professor. As políticas de formação não vão resolver todos os problemas da educação, mas são fundamentais para a melhoria da qualidade de ensino. É necessário que os docentes tenham condições - estruturais inclusive - para participar de um processo formativo tendo em vista a autoria de seu trabalho.

Para isso, faz-se necessário reorganizar a carga horária dos docentes possibilitando que todos possam não apenas ministrar aulas, mas participar de cursos, debates, seminários, fóruns, eventos educativos e formar-se como sujeito-cidadão que reconhece o caráter social e político de sua profissão, que não se resume a uma tarefa técnica. Ser professor não é apenas implantar políticas definidas por aqueles que muitas vezes estão distantes do cotidiano escolar, da mesma forma, alfabetizar não é apenas uma questão de método para enfrentar os resultados insatisfatórios dos exames unificados.

É chegado o momento de termos políticas públicas definidas com a ampla participação dos docentes e com a implantação de programas eficientes de formação profissional.

\section{Referências bibliográficas}

ARROYO, Miguel Gonzalez (2000). Ofício de mestre: imagens e autoimagens. Petrópolis, RJ: Vozes.

FREIRE, Paulo (1992). Pedagogia da esperança. Um reencontro com a pedagogia do oprimido. Rio de Janeiro: Paz e Terra.

FREIRE, Paulo (1995). A Educação na Cidade. 2. ed. São Paulo: Cortez Editora.

FREIRE Paulo (2001). Direitos humanos e educação libertadora. In: FREIRE, A. Madalena A. (Org.). Pedagogia dos sonhos possíveis. São Paulo: Editora Unesp. 
LIMA, Licínio Carlos (2001). A escola como organização educativa: uma abordagem sociológica. São Paulo: Cortez.

MARTINS, Ângela Maria (2002). Autonomia na escola: a (ex)tensão do tema nas políticas públicas. São Paulo: Cortez.

SEVERINO, Antonio Joaquim (2001). Educação, sujeito e história. São Paulo: Olho D'água.

SILVA, Tomaz Tadeu da (2002). Documentos de identidade: uma introdução às teorias do currículo. Belo Horizonte: Autêntica.

\section{Autora}

\section{Elisabete Ferreira Esteves Campos}

Faculdade de Educação da Universidade de São Paulo.

betecampos@terra.com.br

\section{Como citar este artigo:}

CAMPOS, Elisabete Ferreira Esteves. Políticas públicas em educação: uma proposta participativa de formação de professores. Revista ACOALFAplp: Acolhendo a Alfabetização nos Países de Língua portuguesa, São Paulo, ano 2, n. 3, 2007. Disponível em: <http://www.mocambras.org> e ou <http://www.acoalfaplp.org>. Publicado em: setembro 2007. 